\title{
Redescrição e transferência do gênero Fregolia Gounelle, 1911 para Callidiopini (Coleoptera, Cerambycidae) ${ }^{1}$
}

\author{
Jose Ricardo M. Mermudes² \\ Dilma Solange Napp ${ }^{2}$
}

\begin{abstract}
Redescription and transference of the genus Fregolia Gounelle, 1911 to Callidiopini (Coleoptera, Cerambycidae). The genus Fregolia is transferred from Cleomenini Lacordaire, 1869 to Callidiopini Lacordaire, 1869. The genus and its type species, Fregolia listropteroides Gounelle, 1911, the only known species to the genus, are redescribed including characters of the mouth pieces, endosternites, wing venation, and male and female terminalia.
\end{abstract}

Keywords. Cerambycinae; Callidiopini; Cleomenini; Fregolia; taxonomy.

\section{INTRODUÇÃO}

GounELLE (1911), ao estabelecer Fregolia, alertou que este gênero, aparentemente semelhante a Listroptera AudinetServille, 1834, apresentava caracteres anatômicos muito distintos dos demais Cleomenini, como: olhos grosseiramente facetados; antenômero III mais curto que os demais; élitros sem carenas laterais e não-serreados nas margens externas; pernas e tarsos curtos, os metafêmures longe de atingir as extremidades dos élitros.

MERMUdes (1999) no estudo comparado da morfologia dos Cleomenini neotropicais, evidenciou inúmeros caracteres estruturais que distinguiam Fregolia dos demais gêneros e também de Cleomenes e de outros representantes nãoneotropicais da tribo, e sugeriu que Fregolia deveria ser alocado entre os Cerambycinae com olhos grosseiramente facetados.

Corroborando Mermudes (1999), Fregolia é tentativamente transferido para a tribo Callidiopini Lacordaire, 1869, caracterizada pela seguinte combinação de caracteres: olhos grosseiramente facetados, cabeça não-rostrada, tubérculos anteníferos não-projetados, área malar curta, antenas inermes, cavidades cotilóides anteriores não-angulosas, as intermediárias fechadas aos lados (LACORDAIRE 1869).

O material estudado pertence ao Departamento de Zoologia, Universidade Federal do Paraná, Curitiba (DZUP). Técnicas de dissecção e terminologia seguem Mermudes (1999) e NAPP (1994).
Fregolia Gounelle, 1911

Fregolia Gounelle, 1911: 192; Viana, 1972: 9 (redescrição); Monné, 1993: 78 (cat.)

Espécie-tipo: Fregolia listropteroides Gounelle, 1911, monotipia.

Cabeça (Figs. 1-3) não-rostrada. Fronte transversa e curta. Alvéolos antenais moderadamente afastados da inserção das mandíbulas. Clípeo transverso. Labro (Fig. 4) com lados arredondados, bordo apical ligeiramente chanfrado e deprimido no meio. Área malar com cerca de um quinto do diâmetro do lobo ocular inferior. Olhos (Figs. 1-3) grosseiramente facetados, os omatídios fortemente destacados; lobos inferiores ocupam toda a região lateral da cabeça, aproximados na face ventral; lobos oculares superiores estreitos, ultrapassam a margem interna dos tubérculos anteníferos. Estes arredondados e pouco proeminentes. Região posterior da cabeça aplanado no dorso, os lados com constrição nítida e sinuosamente convergentes para trás. Submento curto e transverso. Suturas gulares curtas e convergentes. Mandíbulas (Figs. 5-7) falciformes, pelo menos uma vez e meia mais longas que largas, fortemente angulosas no terço apical e com ápice projetado; franja de pêlos do bordo interno bem desenvolvida do terço anterior até a base. Maxilas (Fig. 8): estipe transverso, dividido em basistipe e dististipe; gálea cilíndrica, alcança, no máximo, a base do terceiro artículo do palpo, pouco expandida na porção apical e obliquamente truncada no ápice; região apical com área deprimida e densamente pilosa; lacínia desenvolvida, a margem interna oblíqua para o ápice. Palpos maxilares 

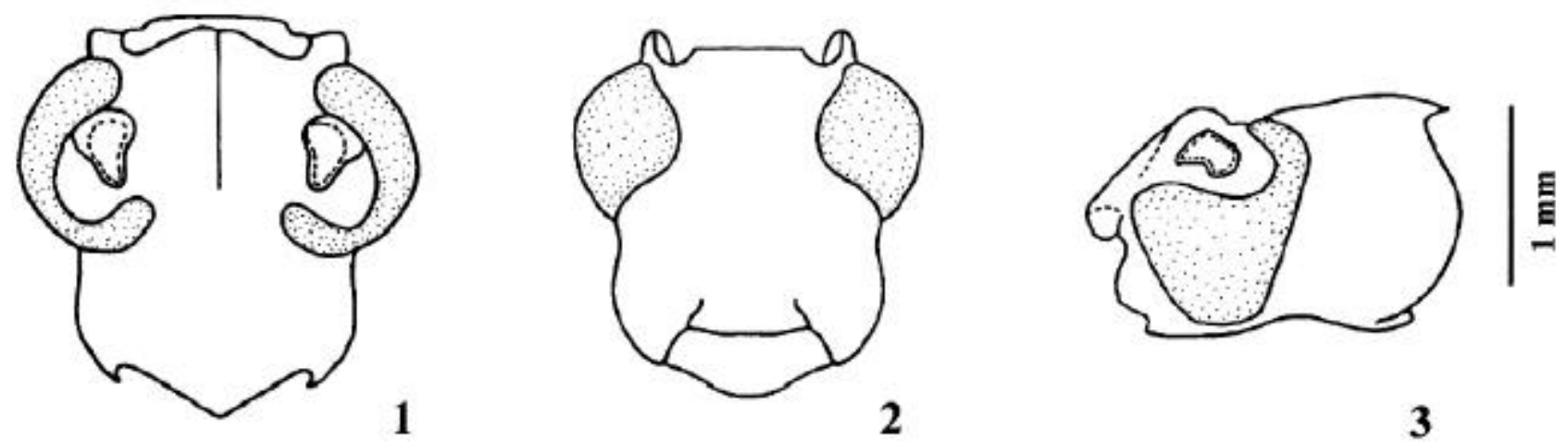

2

3

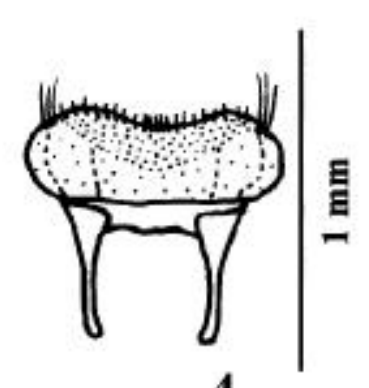

4

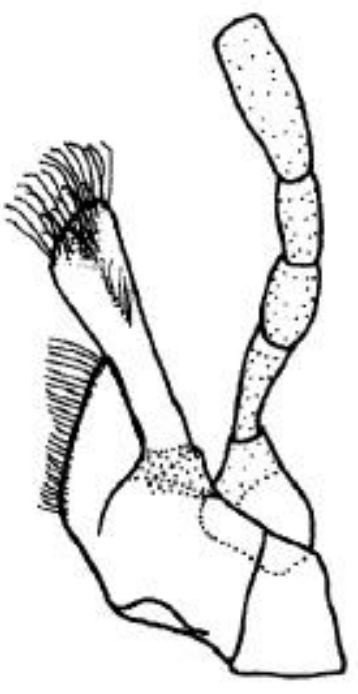

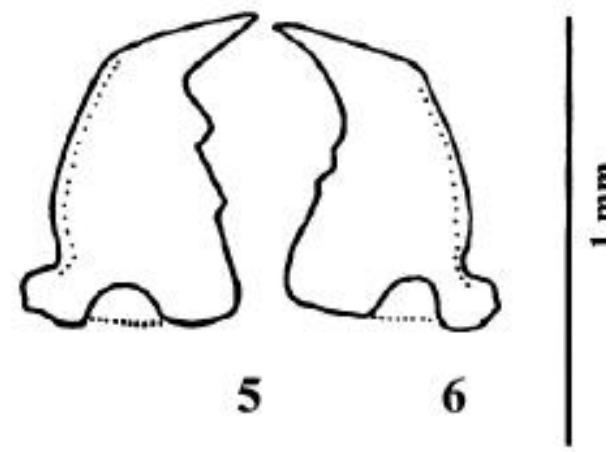
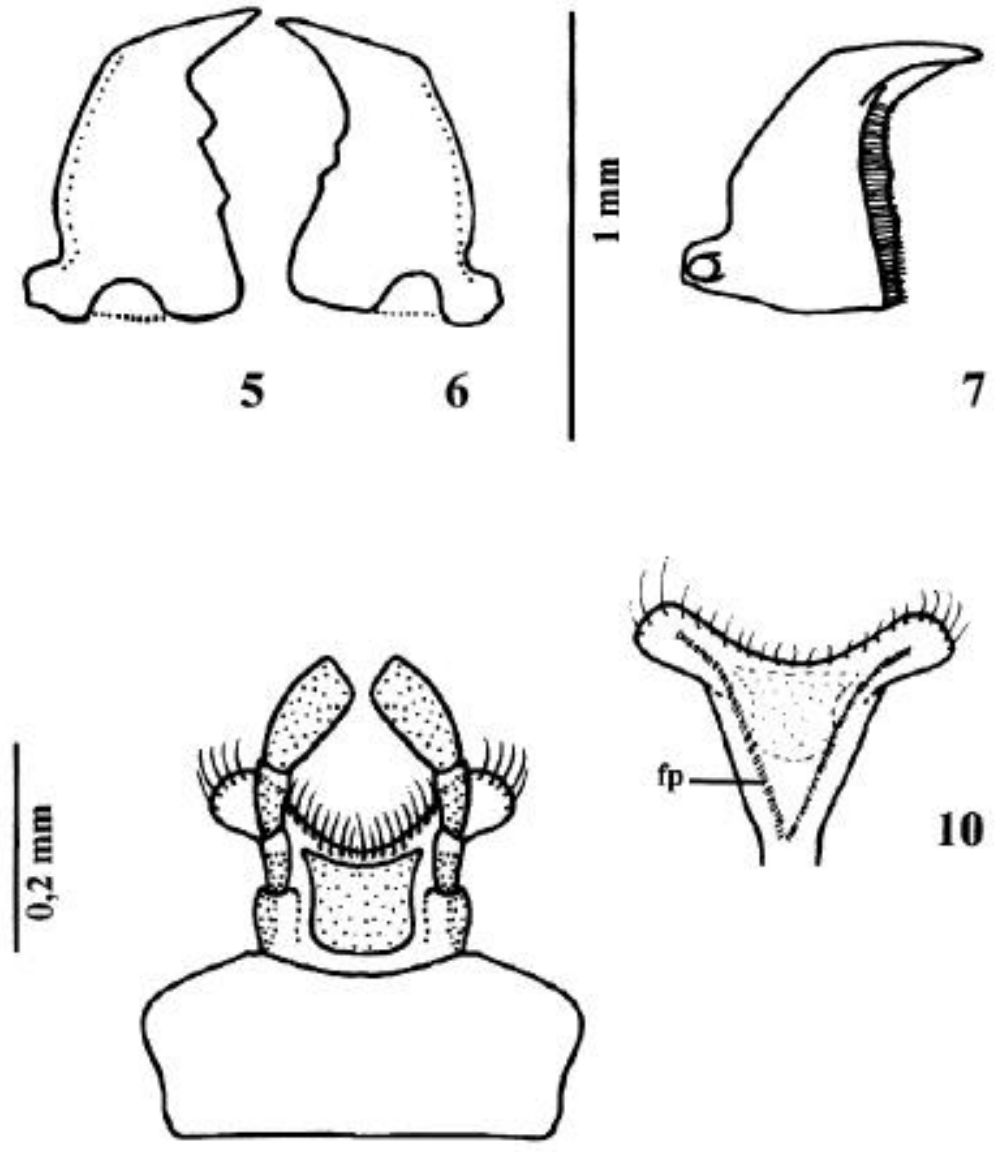

9

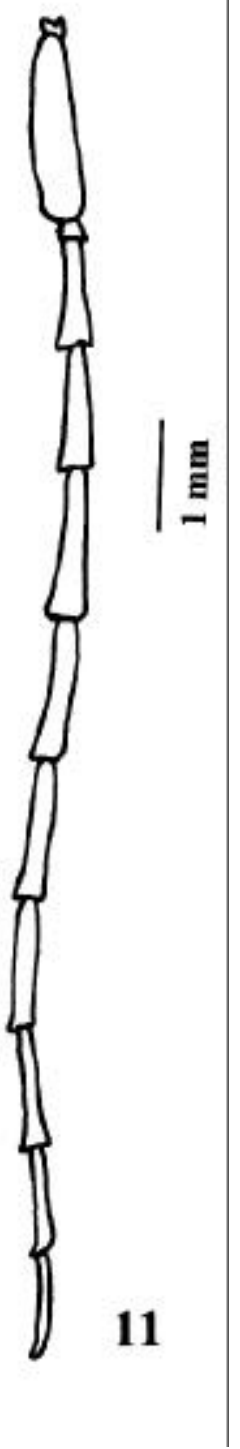

Figs. 1-11. Fregolia listropteroides Gounelle, 1911, macho: 1-3, cabeça, vistas dorsal, ventral e lateral; 4, labro, vista dorsal; 5-7, mandíbulas, 5-6 vista dorsal, 7, vista ventral; 8, maxila; 9, lábio; 10, face interna da lígula; 11, antena; fp = franja de pêlos. Figs. 1-3, 5-7, 8-10, respectivamente, na mesma escala. 
alongados; artículo apical cilíndrico, não atenuado no ápice e mais longo que o basal; segundo e terceiro com comprimentos subiguais. Lábio (Fig. 9): mento transverso e fortemente esclerotizado, região membranosa anterior ausente. Lígula com chanfro raso e largo no bordo apical, este com pilosidade pouco alongada e abundante; lobos laterais alcançam a metade basal do segundo artículo do palpo; face externa com placa mediana desenvolvida, fortemente esclerotizada e brilhante, com pêlos curtos na margem anterior; face interna (Fig. 10) com fileira lateral de pilosidade curta; palpígeros individualizados; artículo apical dos palpos cilíndrico, truncado no ápice; primeiro e segundo artículos subiguais em comprimento, mais curtos que o apical.

Antenas (Figs. 11, 34) filiformes, com 11 artículos, desarmadas, sem sulcos ou carenas. Antenômeros III-X discretamente expandidos no ápice externo. Escapo engrossado e com o dobro do comprimento do III, este mais curto que os seguintes.

Protórax (Figs. 12-15) mais longo que largo, projetado aos lados ao nível do meio, constrito no terço anterior. Processo prosternal estreito entre as coxas, alargando-se bruscamente em direção ao ápice, este levemente sinuoso. Cavidades cotilóides anteriores arredondadas aos lados e fechadas atrás. Proendosternito (Fig. 15) triangular e fusionado na linha média. Processo mesosternal (Fig. 16) moderadamente elevado em relação ao mesosterno, com largura subigual ao diâmetro da cavidade cotilóide, os lados subparalelos, com entalhe mediano no bordo apical para encaixe do metasterno. Cavidades cotilóides médias fechadas aos lados. Mesoscuto (Fig. 17) com área estridulatória retangular. Mesendosternito (Fig. 18) fortemente esclerotizado, a parte distal pouco mais longa que a basal e não fusionada no ápice à parede interna do mesepimero; projeção lateral para implante dos tendões bem aparentes. Metepisterno (Fig. 21) sinuosamente estreitado para trás, truncado no ápice, com duas regiões distintas: metade inferior fortemente esclerosada com textura e escultura iguais às do metasterno, a superior pouco esclerotizada e pigmentada. Metendosternito (Figs. 19, 20) com lâminas muito alongadas e dirigidas para trás e chanfro muito acentuado; tendões anteriores bem distanciados entre si; braços curtos, muito distantes entre si, oblíquos às lâminas; pedúnculo alongado, não fusionado à parede interna do metasterno. Élitros (Fig. 34) sem carena dorsal; lados paralelos até a curvatura apical; epipleuras declives, não-carenadas e não-serreadas na margem externa. Asa (Fig. 23): região apical subigual à metade do comprimento da região basal; célula da Radial fechada, reduzida e de aspecto triangular; r-s perpendicular à Radial; Setor (S) reduzida; Setor Anterior (SA) sinuosa; Média Anterior ausente; s-m retilínea, mais longa que a distância entre a Média e a Cubital; Média (M) reduzida; Plical (P) longa e encurvada na base em direção à Cubital; ramo "a" da Empusal (Ea) unido à Plical; transversal 2Aa bem definida; $\mathrm{Ea}+1 \mathrm{~A}$ com comprimento subigual ao ramo $1 \mathrm{~A}+2 \mathrm{~A} ; 2 \mathrm{Ab}$ reduzida; árculo presente e bem definido; área carenada ausente; lobo anal não-reduzido. Pernas (Fig. 34) curtas, as posteriores um terço mais longas que as anteriores. Fêmures subcilíndricos, pouco engrossados para o ápice, sem sulcos ou carenas, as abas apicais arredondadas. Metafêmures não atingem ápice elitral. Tíbias cilíndrico-deprimidas, não-carenadas. Tarsos curtos, os posteriores tão longos quanto os anteriores. Primeiro metatarsômero mais curto que os dois seguintes reunidos. Escovas tarsais sem faixa glabra. Empódio (Fig. 22) pouco desenvolvido e sem cerdas. Abdômen (Fig. 24) cilíndrico e alongado; urosternito I mais curto que os dois seguintes reunidos, a projeção intercoxal aguçada.

Discussão. Mermudes (1999), Mermudes \& Napp (2000) e NAPP \& Mermudes (2001 a, b) apontaram evidências de homogeneidade morfológica entre os gêneros Listroptera Audinet-Serville, 1834, Dihammaphora Chevrolat, 1859, Haenkea Tippmann, 1953, Aguassay Napp \& Mermudes, 2001 e Timabiara Napp \& Mermudes, 2001, todos alocados na tribo Cleomenini.

Fregolia distingue-se deste grupo de gêneros e também de Pandrosos Bates, 1867, Dihammaphoroides Zajciw, 1967 e de Cleomenes, Thomson, 1864 pela combinação dos seguintes caracteres: 1) cabeça sem rostro, olhos grosseiramente facetados, os lobos inferiores muito desenvolvidos; 2) peças bucais: mandíbulas longas e falciformes; gálea mais curta que o palpo maxilar, este com o artículo apical alongado; lígula curta, com lobos laterais pouco desenvolvidos; 3) antenas: escapo sem sulco dorsal e mais longo que o antenômero III, este mais curto que os seguintes; 4) proendosternito triangular; 5) mesendosternito com projeções para implante dos tendões desenvolvidas, e não-fusionado ao mesepimero no ápice; 6) metendosternito não fusionado à parede interna do metasterno, com lâminas muito mais longas que os braços, com chanfro acentuado; 7) élitros: não-carenados no dorso, as epipleuras gradualmente declives, sem carenas e não-serreadas; 8) asas: lobo anal não-reduzido; Plical longa e encurvada em direção à Cubital; ramo "a" da Empusal (Ea) presente, unido à Plical; área carenada ausente; Média (M) afastada da Cubital; célula da Radial fechada e reduzida; s-m retilínea; 9) pernas e tarsos curtos, os fêmures lineares, sem sulcos ou carenas; metafêmures alcançam a margem apical do urosternito III; 10) abdômen cilíndrico e alongado; urosternito I pouco mais longo que o seguinte, a projeção intercoxal aguçada.

Esse conjunto de caracteres não permite a manutenção de Fregolia em Cleomenini e, em parte, justifica sua inclusão, ainda que provisória, em Callidiopini.

Fregolia listropteroides Gounelle, 1911 (Figs. 1-34)

Fregolia listropteroides Gounelle, 1911: 192, fig.1; Viana, 1972: 11, 1 fig. (redescrição); Monné, 1993: 78 (cat.).

Macho. Tegumento geral preto a castanho-escuro, dorso dos élitros pouco mais claro. Pronoto, região posterior da cabeça e orla anterior do prosterno, alaranjados. Região mediana da base do pronoto preta.

Fronte convexa, intumescida na inserção com o clípeo e 


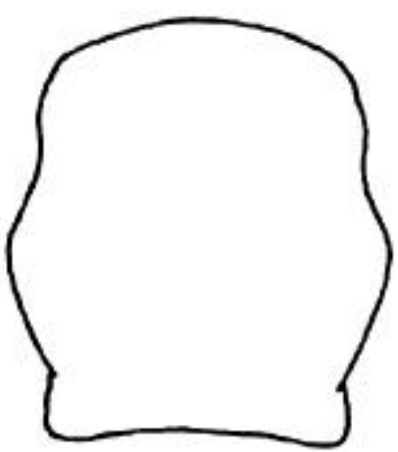

12

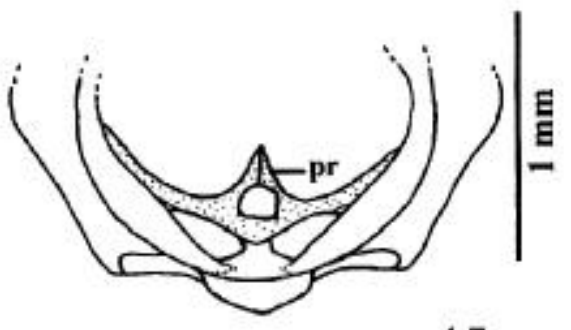

15

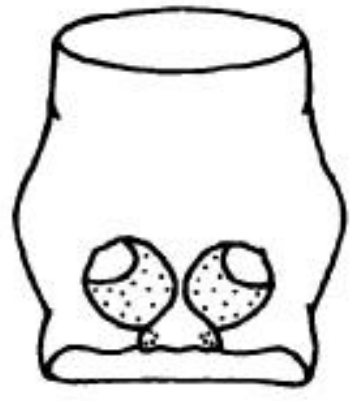

13

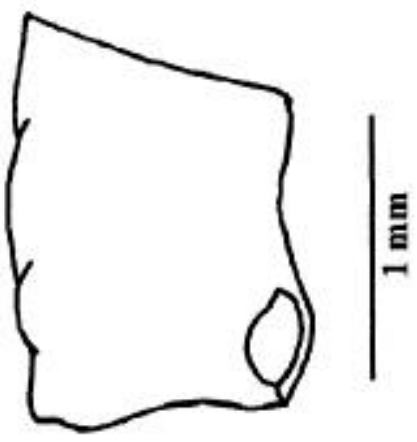

14

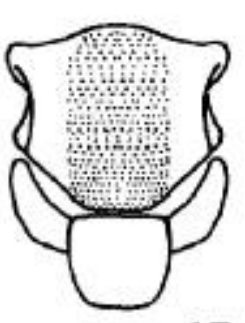

16

17

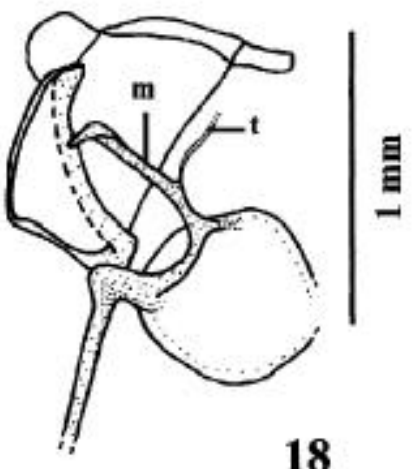

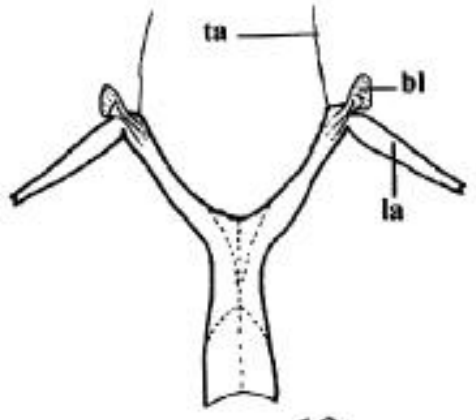

19

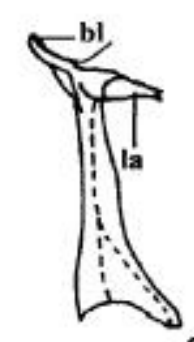

20

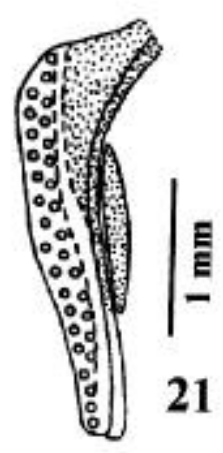

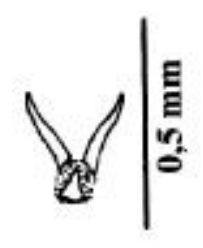

22

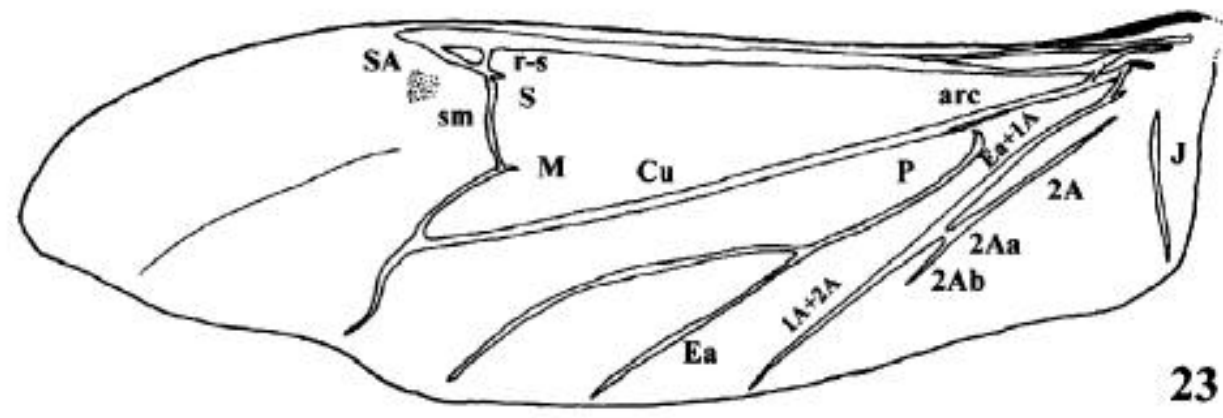

E

Figs. 12-23. Fregolia listropteroides Gounelle, 1911, macho: 12-15, protórax, vistas dorsal, ventral, lateral e posterior; 16, mesosterno; 17, mesoscuto e escutelo; 18, mesendosternito; 19-20, metendosternito, vistas superior e lateral; 21, metepisterno; 22, empódio; 23, asa membranosa; arc = árculo; $\mathrm{bl}=$ braços laterais $; \mathrm{Cu}=\mathrm{Cubital} ; \mathrm{Ea}=$ ramo a da Empusal; $\mathrm{J}=\mathrm{Jugal} ; \mathrm{la}=$ lâminas; $\mathrm{M}=\mathrm{Média} ; \mathrm{m}=$ mesendosternito; $\mathrm{P}=\mathrm{Plical} ; \mathrm{pr}=$ proendosternito; $\mathrm{r}-\mathrm{s}=$ transversa radial-média; $\mathrm{S}=\mathrm{Setor} ; \mathrm{SA}=$ Setor Anterior; $\mathrm{sm}=$ transversa setor-média; $\mathrm{t}=$ tendões; ta $=$ tendões anteriores; $1 \mathrm{~A}$ $=1^{\mathrm{a}}$ anal; $2 \mathrm{~A}=2^{\mathrm{a}}$ anal; $2 \mathrm{Aa}=$ ramo da $2 \mathrm{~A} ; 2 \mathrm{Ab}=$ ramo da $2 \mathrm{~A}$. Figs. $12-14,15$ e $17,18-20$, respectivamente, na mesma escala. 

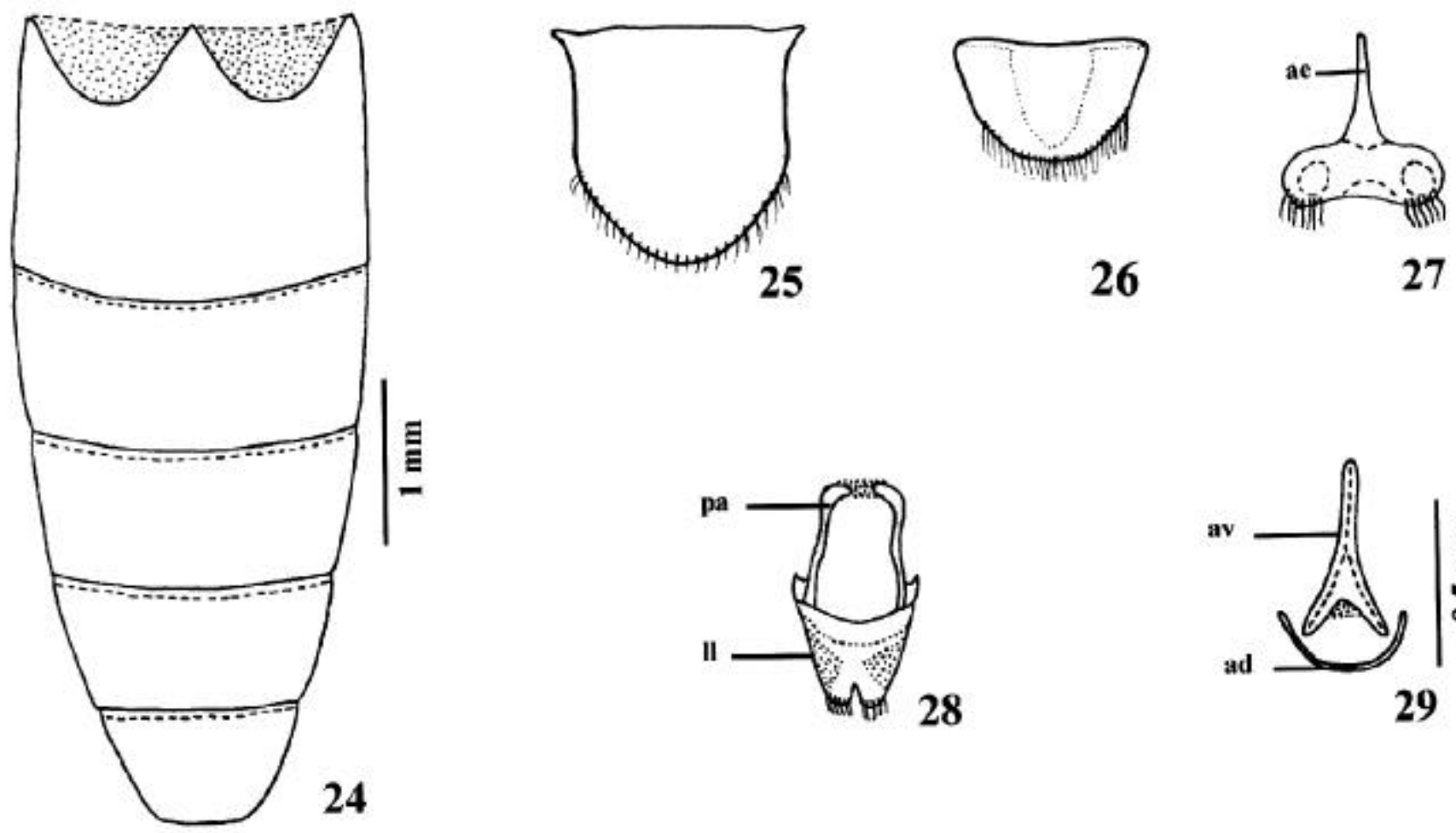

26


Figs. 24-33. Fregolia listropteroides Gounelle, 1911. Macho, 24-30: 24, abdômen, vista ventral; 25, sétimo tergito; 26, oitavo tergito; 27, oitavo esternito; 28, tégmen; 29, arcos dorsal e ventral; 30, lobo médio. Fêmea, 31-33: 31, oitavo tergito; 32, oitavo esternito; 33, ovipositor; ab = apófises basais; ad = arco dorsal; ae = apófise esternal; av = arco ventral; $1 \mathrm{~b}=$ lobo dorsal; 11 = lobos laterais; lv = lobo ventral; pa = peça anelar. Figs. 25-29, 31 e $32 ; 30$ e 33 , respectivamente, na mesma escala. 


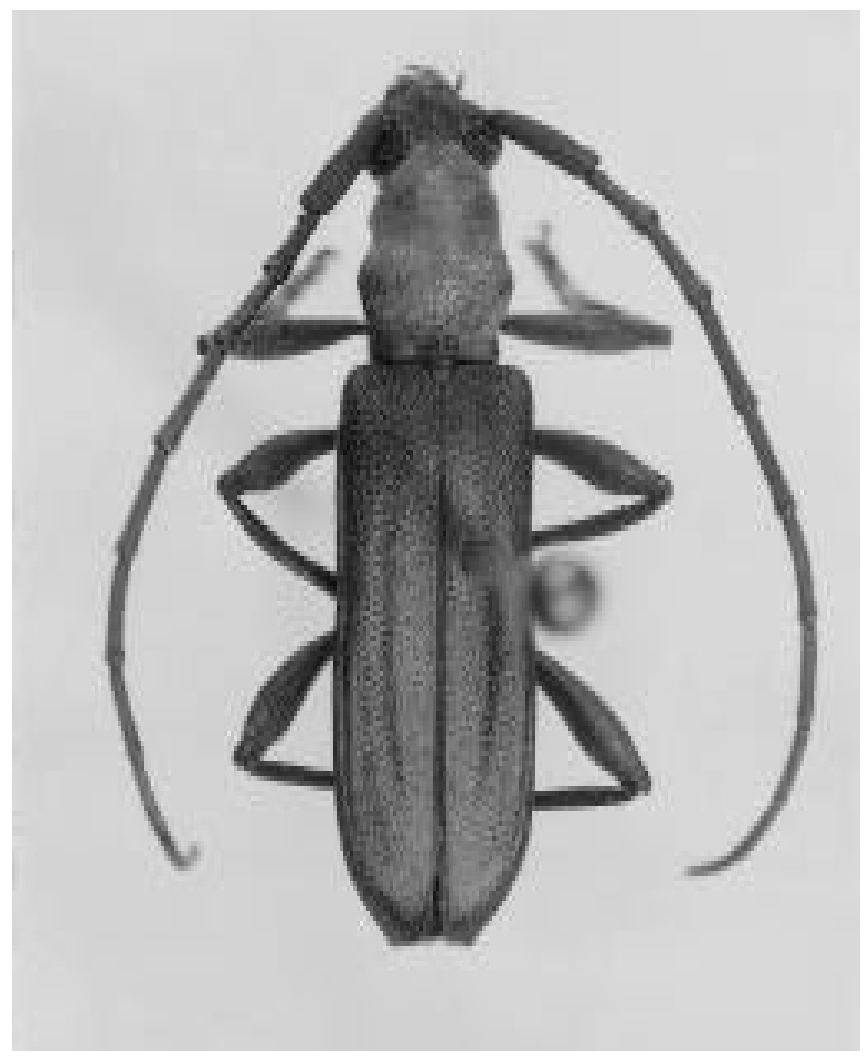

Fig. 34. Fregolia listropteroides Gounelle, 1911, macho, de Seara (= Nova Teutônia), Santa Catarina, comprimento, 9,6 mm.

carenada aos lados; glabra, com pontos grossos e contíguos, aspecto foveolado. Região entre tubérculos anteníferos e margem posterior dos olhos com escultura semelhante à da fronte. Área malar corrugada; superfície ventral com fortes rugas transversais e pontos grossos. Mento coriáceo, densamente microcorrugado e com pontos grossos. Vértice revestido por pubescência sedosa alaranjada, oblitera o tegumento. Distância entre os tubérculos anteníferos cerca de 1,5 vezes a distância entre os lobos oculares superiores. Mandíbulas (Figs. 5-7) fortemente corrugadas; bordo interno da mandíbula esquerda com dois dentes, o mais próximo do ápice com aspecto discretamente rombóide e pouco mais desenvolvido que o dente submediano; dentes da mandíbula direita quase nulos.

Antenas (Figs. 11, 34) ultrapassam o ápice elitral em um antenômero. Escapo forte e densamente pontuado-corrugado, subglabro. Antenômeros III-XI com micropubescência branca, brilhante e progressivamente adensada para os distais. Antenômeros II-XI densamente micropontuados. Antenômero III mais curto que o IV e um terço mais curto que os V-VI; antenômeros VII-XI discretamente decrescentes no seu comprimento; o XI apendiculado, pouco mais longo que o III.

Protórax com pontuação grossa, profunda e densa em toda a superfície, os pontos rasos e menos aparentes no pronoto. Pronoto elevado no disco e com quatro gibosidades, as anteriores pouco mais amplas e mais distantes entre si; revestido com pubescência alaranjada, brilhante, decumbente, quase oblitera o tegumento. Face ventral com micropubescência esbranquiçada em toda a superfície, mais evidente nos urosternitos. Prosterno microesculturado, sem pontuação sexual. Mesosterno e metasterno microesculturados e com pontos grossos, profundos e densos em toda a superfície. Escutelo (Fig. 17) tão largo quanto longo, truncadoarredondado no ápice, com pubescência amarelada e brilhante. Élitros (Fig. 34) moderadamente alongados, os úmeros não projetados; ligeiramente gibosos aos lados da sutura após o escutelo; região da costa dorsal representada por um sulco glabro; ápices estreitados; pontuação grossa e densa, os pontos subcontíguos e até foveolados no terço basal; os dois terços distais revestidos por pubescência esbranquiçada que oblitera o tegumento; epipleuras ligeiramente deprimidas e fortemente pontuadas. Fêmures robustos, densamente pontuado-corrugados. Metafêmures alcançam a margem apical do urosternito III. Tíbias fina e densamente pontuadocorrugadas, pilosidade pouco aparente; esporões tibiais curtos e subiguais.

Urosternitos com pontos grossos e densos. Urosternito V (Fig. 24) transverso, lados convergentes, truncado no ápice. Sétimo tergito (Fig. 25) mais longo que largo, lados convergentes no terço apical, ápice arredondado.

Terminália. Oitavo tergito (Fig. 26) transverso, bordos laterais ligeiramente convergentes para a margem apical, esta amplamente arredondada; oitavo esternito (Fig. 27) fortemente transverso, com o bordo apical algo emarginado; apófise esternal nitidamente mais longa que o esternito, alargada na base. Arco ventral (Fig. 29) com ângulo raso na porção bifurcada, esta engrossada e subigual à metade do comprimento da apófise; arco dorsal (Fig. 29) desenvolvido. Tégmen (Fig. 28) com a região distal alargada, dividida em lobos laterais apenas na região apical; peça anelar levemente sinuosa, com o ápice arredondado, não-fusionado, os braços laterais, neste ponto, ligados pela bainha da peça anelar. Lobo médio (Fig. 30) com a região apical subigual à metade do comprimento das apófises basais; lobo dorsal mais longo que o ventral, com lados convergentes na região apical, ápice acuminado; lobo ventral com ápice bissinuado. Saco interno muito alongado, com duas regiões espiculadas e dois pares de peças esclerotinizadas na altura do forâmen médio.

Fêmea. Artículos antenais mais delgados. Protórax mais longo e estreito. Pronoto com gibosidades anteriores usualmente mais aguçadas. Fêmures mais delgados e lineares. Urosternito $\mathrm{V}$ mais alongado, com lados convergentes, arredondado no ápice. Terminália: oitavo segmento (Figs. 31, 32) tão largo quanto longo, lados subparalelos, truncado no ápice; apófise esternal cerca de três vezes mais longa que o esternito. Ovipositor (Fig. 33) alongado, membranoso; região distal bem mais curta que a proximal; estilos subcilíndricos, apicais; baculi dorsais e ventrais subiguais no comprimento. Espermateca alongada, curvada apenas no ápice. Ápodemas na base do oviduto comum e órgãos impregnadores de simbiontes, ausentes.

Dimensões, em mm, macho/fêmea, respectivamente. 
Comprimento total, 9,20-10,5/8,5-10,3; comprimento do protórax, 1,8-2,2/1,7-2,0; largura do protórax, 1,5-1,8/1,3-1,8; comprimento do élitro, 6,3-7,3/5,8-7,2; largura umeral 2,0-2,3/1,6-2,3.

Material-tipo. A série sintípica constitui-se de 7 exemplares machos e 5 fêmeas, procedentes de Jataí, Goiás, Brasil (Gounelle 1911), depositados no Museúm National d'Histoire Naturelle, Paris. Um síntipo macho foi examinado por meio de diapositivo.

Distribuição. Brasil (Goiás, Mato Grosso, Pernambuco ao Rio Grande do Sul) e Argentina (Misiones) (Viana 1972; MonNÉ 1993).

Material examinado. Brasil, Bahia: Condeuba, 1 fêmea, II.976, Souza col. Espírito Santo: Linhares, 1 macho e 1 fêmea, 22-31.X.1972, C. T. \& C. Elias col. Paraná: Ponta Grossa, 1 macho, XII.1950, 1 fêmea, II.1976, ex-coleção F. Justus. Santa Catarina: Seara (= Nova Teutônia), 1 macho e 1 fêmea, X.1972, 2 machos e 3 fêmeas, IX.1973, F. Plaumann col. (DZUP).

Agradecimentos. A Miguel A. Monné (Museu Nacional, UFRJ) e U. R. Martins (Museu de Zoologia, USP) pelas discussões e sugestões sobre a posição taxonômica de Fregolia. A Albino M. Sakakibara (DZUP) pela execução da foto.

\section{REFERÊNCIAS}

Gounelle, E. 1911. Liste des Cérambycides de la région de Jatahy, Etat de Goyaz, Brésil. Annales de la Société Entomologique de France 80: $103-252$.

Lacordaire, J. T. 1869. Histoire Naturelle des Insectes. Genera des Coléoptères. Paris, Librairie Encyclopedique de Roret, 8: 1-552; 9: 1-409.

Mermudes, J. R. M. 1999. Morfologia comparada dos gêneros neotropicais de Cleomenini Lacordaire, 1869 (Coleoptera, Cerambycidae, Cerambycinae). Tese de Mestrado, Universidade Federal do Paraná, Curitiba, xii +89 p.

Mermudes, J. R. M. \& D. S. NAPP. 2000. Review of the genus Haenkea Tippmann (Coleoptera, Cerambycidae, Cerambycinae, Cleomenini). Coleopterists Bulletin 54 (4): 511-519.

Monné, M. A. 1993. Catalogue of the Cerambycidae (Coleoptera) of the Western Hemisphere. Part IX. São Paulo, Sociedade Brasileira de Entomologia, $131 \mathrm{p}$.

NAPP, D. S. 1994. Phylogenetic relationships among the subfamilies of Cerambycidae (Coleoptera, Chrysomeloidea). Revista Brasileira de Entomologia 32 (2): 265-419.

NAPP, D. S. \& J. R. M. Mermudes. 2001a. Revision of the genus Listroptera Audinet-Serville and description of Aguassay, new genus (Coleoptera, Cerambycidae, Cleomenini). Coleopterists Bulletin 55 (1): 1-9.

Napp, D. S. \& J. R. M. Mermudes. 2001b. New South American genus and species of Cleomenini (Coleoptera, Cerambycidae). Revista Brasileira de Zoologia 18 (Supl. 1): 61-66.

VIAna, M. J. 1972. Fregolia listropteroides Gounelle, nuevo gênero y especie de Cleomenini para la Republica Argentina (Coleoptera, Cerambycidae). Neotropica 18 (55): 9-15. 